The Open Dentistry Journal
Bentham open
CrossMark
Dont $10.2174 / 1874210601610010610$

\title{
LETTER
}

\section{An Optical System to Monitor the Displacement Field of Glass-fibre Posts Subjected to Thermal Loading}

\author{
Massimo Corsalini ${ }^{1}$, Francesco Pettini ${ }^{1}$, Daniela Di Venere ${ }^{1}$, Andrea Ballini ${ }^{2}$, Giuseppe Chiatante, \\ Luciano Lamberti ${ }^{4}$, Carmine Pappalettere ${ }^{4}$, Michele Fiorentino ${ }^{4}$, Antonio E. Uva ${ }^{4}$, Giuseppe Monno ${ }^{4}$ \\ and Antonio Boccaccio, \\ ${ }^{I}$ Interdisciplinary Department of Medicine, University of Bari Aldo Moro, 70124 Bari, Italy \\ ${ }^{2}$ Department of Basic Medical Sciences, Neurosciences and Sensory Organs, University of Bari Aldo Moro, 70124 Bari, \\ Italy \\ ${ }^{3}$ School of Dentistry, University of Chieti "G. d'Annunzio", 66100 Chieti, Italy \\ ${ }^{4}$ Department of Mechanics, Mathematics and Management, Politecnico di Bari, 70126 Bari, Italy
}

\begin{abstract}
Endocanalar posts are necessary to build up and retain coronal restorations but they do not reinforce dental roots. It was observed that the dislodgement of post-retained restorations commonly occurs after several years of function and long-term retention may be influenced by various factors such as temperature changes. Temperature changes, in fact, produce micrometric deformations of post and surrounding tissues/materials that may generate high stress concentrations at the interface thus leading to failure.

In this study we present an optical system based on the projection moiré technique that has been utilized to monitor the displacement field of endocanalar glass-fibre posts subjected to temperature changes.

Measurements were performed on forty samples and the average displacement values registered at the apical and middle region were determined for six different temperature levels. A total of 480 displacement measurements was hence performed.

The values of the standard deviation computed for each of the tested temperatures over the forty samples appear reasonably small which proves the robustness and the reliability of the proposed optical technique. The possible implications for the use of the system in the applicative context were discussed.
\end{abstract}

Keywords: Dental materials, Endocanalar post, Projection moiré, Thermal deformation, Thermal stress.

\section{INTRODUCTION}

Endodontically-treated teeth may run a higher risk of failure than vital teeth $[1,2]$. Although posts are necessary to retain coronal build-up materials, they do not reinforce roots and may even weaken them through loss of radicular dentin necessitated by post-space preparation [3 - 5]. Some authors asserted that posts may interfere with the mechanical resistance of treated teeth thus leading to an increased risk of damage for residual tooth structure [6 - 10].

Some studies have reported that fiber-reinforced resin posts provide lower retention in comparison with metal posts $[11,12]$. Conversely, other studies reported no significant differences between the retention of fiber-reinforced resin and metal posts $[13,14]$. Among the fiber-reinforced resin posts, glass-fiber posts play a role of predominant importance. They are composed of glass fibers, inorganic filler and a resin matrix and are usually luted with a resin cement to increase their retention and improve the mechanical performance of the restored teeth [15, 16]. Investigations

* Address correspondence to this author at the Department of Mechanics, Mathematics and Management, DMMM, Politecnico di Bari, Viale Japigia 182, I-70126, Bari, Italy; Tel: +39080 5962705; Fax: +39080 5962777; E-mail: a.boccaccio@poliba.it 
on the effects of different combinations of irrigants and sealers on the shear bond strength at the post-dentine interface have been previously carried out [17, 18]. Finite element models reproducing the structural response of endodontically treated teeth were also developed [19, 20]. From the clinical point of view, it was observed that the dislodgement of post-retained restorations commonly occurs after several years of function, and long-term retention may be influenced by various factors such as temperature changes and dynamic mechanical loading [9, 21 - 23]. In particular, temperature changes produce micrometric deformations of post and adjacent tissues/materials (ATM). When thermal properties of the latter ones significantly differ from those of post, temperature changes may originate high stresses at the post/ATM interface that can lead to failure.

Generally speaking, the interfaces between materials with different physical properties such as the thermal properties, represent areas of weakness as local discrepancies influence stress-strain distribution [8]. A number of studies are available in the literature where the thermal properties of different dental materials are reported [24]. Some of them focused on the measurement of the thermal expansion coefficient [25 - 27], others on thermal conductivity [24, $28,29]$, others on thermal diffusivity [29 - 31] etc. In general, the interaction between two bodies put in contact and subjected to thermal loading is the result of complex phenomena that depend not only on the specific values of the thermal properties but also on the way the thermal properties interact one each other both in stationary and transient conditions. Developing a theoretical model capable of reproducing the structural response of bodies put in contact and subjected to thermal loading is a very difficult task. The models currently available in the literature refer to simplified conditions and geometries that are very far from those actually occurring in the practice. In such a context, an experimental technique capable of monitoring the displacement field produced by a thermal load is of paramount importance not only to assess the structural behavior of the system but also to identify all the possible dental materials that can be put in contact and utilized to fabricate interfaces that, in the presence of thermal loadings, do not undergo to large stress values.

In this article we present an optical system based on the projection moiré technique that allows the displacement field of endocanalar glass-fibre posts subjected to thermal loading to be reconstructed with high accuracy. Projection moiré, the basic optical technique previously utilized with success to contour the shape of objects [32, 33] as well as to analyze the displacement field of industrial components under different boundary and loading conditions [34 - 37] was properly implemented in an ad hoc designed optical set-up aimed at monitoring the displacements of endocanalar posts subjected to temperature changes. The displacement of forty samples was measured. The rather low values of standard deviation prove the reliability of the proposed experimental technique. The possible implications for the use of the system in the applicative context were discussed.

\section{MATERIALS AND METHODS}

\section{Experimental Set-up}

The optical set-up utilized in the study is articulated in two principal branches: the first one includes different optical components and is devoted to the projection of structured, collimated and coherent light onto the sample surface; the second one includes only a CCD camera and is devoted to the acquisition of the projected patterns of lines. All the components of the projection branch, i.e. the laser source, the microscope/pinhole system, the lens 1, the grating, the lens 2, the iris and the lens 3, are aligned with the projection axis (highlighted in red, (Fig. 1) while the optical axis of the CCD camera, that is the only component of the acquisition branch, is aligned with the acquisition axis (highlighted in blue, (Fig. 1). CCD camera is equipped with a long working distance objective. The angle $\vartheta$ made by the projection axis and the acquisition axis utilized in the study was $20^{\circ}$. The laser source ( $35 \mathrm{~mW}, \mathrm{He}-\mathrm{Ne}$, Melles-Griot, Rochester, NY, USA) generates a coherent and polarized light beam that goes through the microscope/pinhole system. The microscope expands the beam while the pinhole removes all the noise effects of the parasitic diffraction phenomena produced during the expansion. The exit pupil of the pinhole is located at the focal distance $F_{D I}=200 \mathrm{~mm}$ of the lens 1 ; with this arrangement, the spherical wave-fronts impinging the lens are converted into planar wave-fronts and hence the light beam coming out from the lens is collimated. This beam first passes through a Ronchi ruling with a pitch of $p=84.67 \mu \mathrm{m}$ and then through the lens 2 with a focal distance $F_{D 2}=300 \mathrm{~mm}$ (Fig. 1). In the focal plane of this lens, the Fourier transform of the light wave-front diffracted by the grating creates. By changing the aperture of the iris - located just in the focal plane of lens 2 -, to select the diffraction orders 0 and one of two orders \pm 1 , a sinusoidal carrier can be produced with the projected grating pitch. The iris is located not only in the focal plane of lens 2 but also in that of lens 3 which is characterized by a focal distance $F_{D 3}=F_{D 2}=300 \mathrm{~mm}$. Therefore, the light beam coming out from the iris is collimated by the lens 3 and the collimated wave front so created and carrying the filtered spectrum of the grating is 
finally projected onto the surface of the endocanalar post (Fig. 1). The patterns of lines projected on the sample surface are acquired by a CCD camera. By equipping the camera with a long working distance objective, the acquired field of view was as large as approximately the post length. A heat gun placed in front of the sample was utilized to blow hot air on the sample surface. A thermocouple located just in the vicinity of the post surface lapped from the hot air was utilized to monitor the sample temperature (Fig. 1).

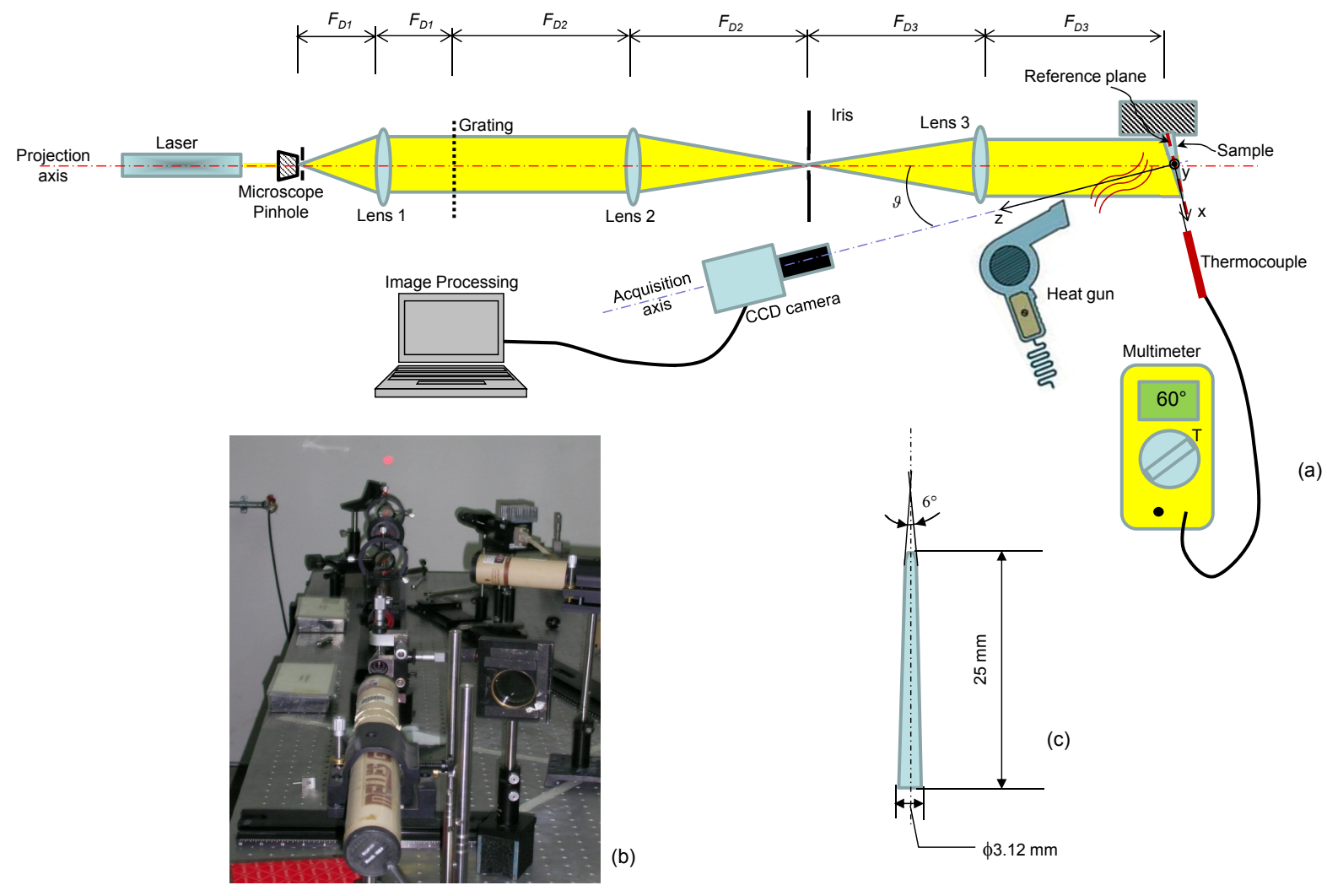

Fig. (1). Schematic (a) and assembly view (b) of the optical set-up utilized to monitor the displacement field of the endocanalar post subjected to thermal loading. (c) Dimensions of the tested samples.

In order to measure the sample displacement during the heating process, by means of the above described optical set-up, two procedures must be carried out: the calibration and the processing of the acquired images. It is worthy to note that the experimental set-up above described allows the sample geometry to be contoured, therefore the displacement field produced by the thermal loading will be calculated as the difference between the sample contour at a given temperature and that at the environment temperature.

\section{Calibration Procedure and Processing of Images}

The calibration procedure requires to project patterns of lines - generated with the projection branch of the optical set-up described above - onto the surface of a reference plane (indicated in Fig. 1a) with a dashed red line) which is the plane with respect to which the depth of all the acquired points of the sample is measured. The acquired images of the projected lines are then processed to extract the phase map. To this purpose, the fast Fourier transform is first calculated, and hence, in the Fourier space, the frequency at which the maximum intensity of the power spectrum is identified. After implementing band-pass filters, the inverse Fourier transform is computed and from the obtained filtered image, through the in-quadrature method, the phase map $\Phi_{\mathrm{REF}}(x, y)$ is extracted. At this point, the reference plane can be removed and replaced by the sample. Again, the patterns of lines are projected onto the sample surface (Fig. 2a) and, adopting the same procedure described above, the filtered image (Fig. 2b) and the phase map (Fig. 2c) of the sample $\Phi_{\text {SAMPLE }}(x, y)$ is extracted. The total phase $\Delta \Phi_{\text {TOT }}(x, y)$ can be hence computed as:

$$
\Delta \Phi_{T O T}(x, y)=\Phi_{R E F}(x, y)-\Phi_{S A M P L E}(x, y)
$$


The height $z(x, y)$ of each point of the sample with respect to the reference plane can be calculated as:

$$
z(x, y)=\Delta S \cdot \frac{\Delta \Phi_{T O T}(x, y)}{2 \cdot \pi}
$$

where the sensitivity $\Delta S$ is a quantity depending on the set-up geometry/arrangement and is given by $\Delta S=p / \sin \vartheta$. In the specific case, it is $\Delta S=247.55 \mu \mathrm{m} /$ fringe.
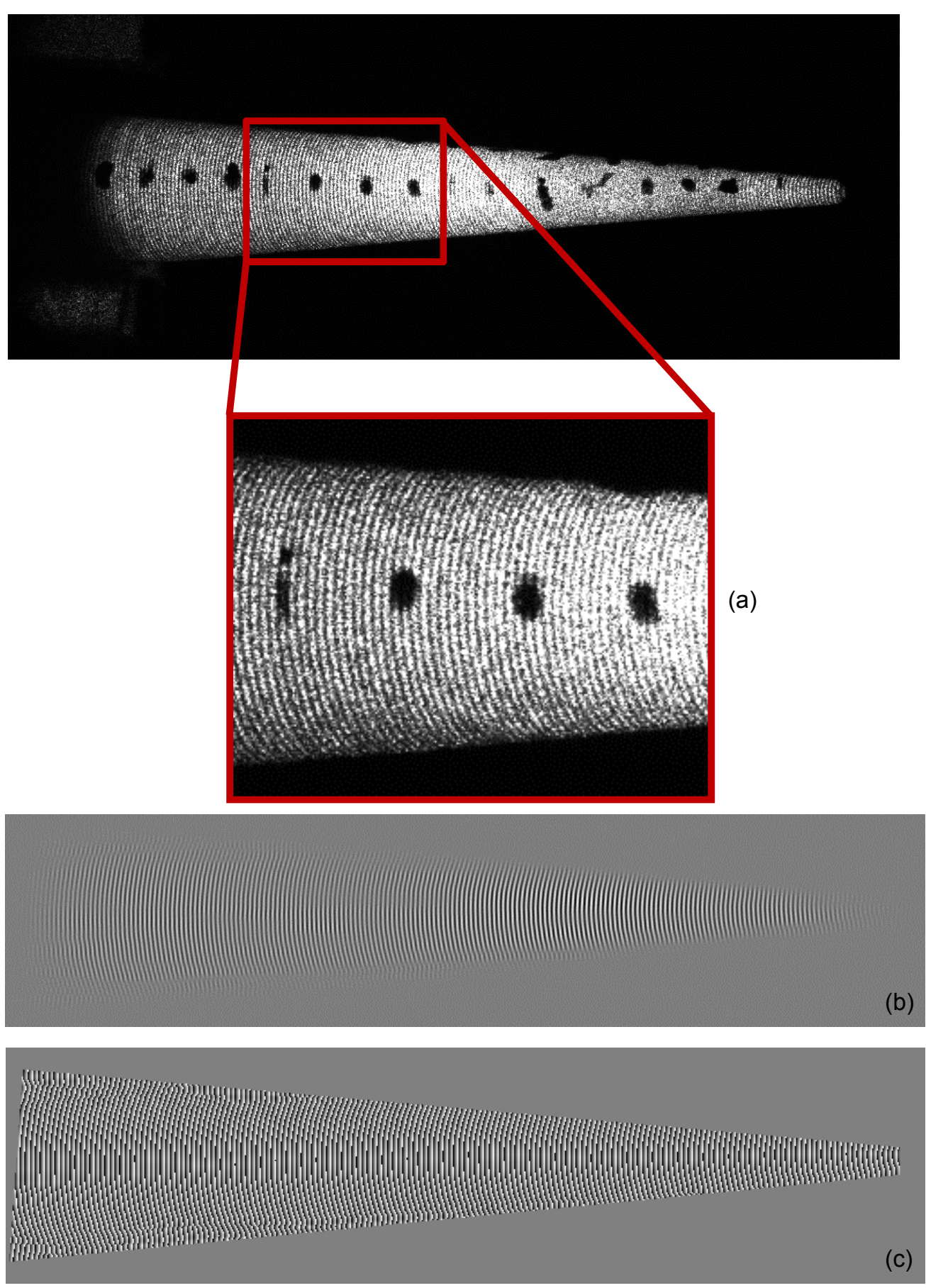

Fig. (2). (a) Lines projected onto the sample surface. (b) Pattern of the projected lines after the filtering process. (c) Phase of the specimen@ $T_{e n v}=18^{\circ} \mathrm{C}$ (environment temperature). 


\section{Experiments}

Forty samples, $25 \mathrm{~mm}$ long with a $6^{\circ}$ conicity angle (Surgi post Multi Conical, Miromed s.r.l., Lainate (MI), Italy), were tested. The samples are shaped as a frustum of cone, the larger base having a diameter of $3.12 \mathrm{~mm}$, the smaller one of $0.5 \mathrm{~mm}$ (Fig. 1c). By means of the optical set-up the post geometry was first acquired at environment temperature $T_{e n v}$ $=18{ }^{\circ} \mathrm{C}$. Then, by using a heat gun placed in front of the sample, hot air was blown on the sample surface thus increasing its temperature. The increase of the temperature produces an inflection of the sample towards the side opposite to where the heat gun is located (Fig. 3a). The post geometry was hence contoured, - i.e. the coordinate $z(x, y)$ (with respect to the reference plane) of each point of the post surface was determined, - at the following six temperatures $T_{\text {post }}: 40,60,80,100,120$ and $150{ }^{\circ} \mathrm{C}$. The acquisition was done as soon as the thermocouple measured the above mentioned temperatures $T_{\text {post }}$. Between two consecutive acquisitions, a 10-minute time interval was waited so that the sample temperature, at the beginning of the new acquisition, is equal to $T_{e n v}$. In order to make sure that no residual deformations were left by thermal loading in the currently tested post, a new image of the post was recorded after the 10-minute temperature recovery interval. This image was digitally superimposed on the reference image of the same post and the corresponding pattern thus generated was carefully analyzed. Since no moiré fringes were seen to form, we concluded that in the present experiments there was never residual deformation between two consecutive measurements performed on the same post.

Let $\mathrm{M}$ and $\mathrm{T}$ be two physical points, placed in the middle and tip section of the sample surface before blowing hot air and $\mathrm{M}^{\prime}$ and $\mathrm{T}^{\prime}$ the same points after the temperature reaches the value $T_{\text {post }}$ (Fig. 3a). If $z\left(x_{\mathrm{M}}, y_{\mathrm{M}}\right)_{T p o s t}$ and $z\left(x_{\mathrm{T}}, y_{\mathrm{T}}\right)_{T p o s t}$ are the heights of the post in correspondence of the points $\mathrm{M}$ and $\mathrm{T}$, respectively, at the temperature $T_{\text {post }}$, and $z\left(x_{\mathrm{M}}, y_{\mathrm{M}}\right)_{\text {Tenv }}$ and $z\left(x_{\mathrm{T}}, y_{\mathrm{T}}\right)_{\text {Tenv }}$ are the heights of the same points at the environment temperature $T_{e n v}$, the displacements $\delta_{\mathrm{M}}$ and $\delta_{\mathrm{T}}$ experienced by these two points at the temperature $T_{\text {post }}$ can be computed as:

$$
\begin{aligned}
& \delta_{\mathrm{M}}=-\left(z\left(x_{M}, y_{M}\right)_{T_{p o s t}}-z\left(x_{M}, y_{M}\right)_{T \text { env }}\right) \\
& \delta_{\mathrm{T}}=-\left(z\left(x_{T}, y_{T}\right)_{T \text { post }}-z\left(x_{T}, y_{T}\right)_{T \text { env }}\right)
\end{aligned}
$$

For each of the six hypothesized values of $T_{p o s t}$, the displacements $\delta_{\mathrm{M}}$ and $\delta_{\mathrm{T}}$ averaged over the forty samples and the standard deviations were computed. A total of 2 (number of points $(\mathrm{M}$ and $\mathrm{T}$ ) where the displacement was measured) $\times$ 6 (number of considered temperature levels) $\times 40$ (number of tested samples) $=480$ measurements were carried out.

\section{RESULTS AND DISCUSSION}

Increasing values of the (average) displacement $\delta_{\mathrm{M}}$ and $\delta_{\mathrm{T}}$ were measured for increasing levels of temperature $T_{\text {post }}$ (Fig. 3b, c). In particular, for a fixed temperature, $\delta_{\mathrm{T}}$ is always greater than $\delta_{\mathrm{M}}$. This is consistent with the physics of the problem. The conical post behaves as a cantilever beam clamped on the larger base, therefore any inflection (that produces the rotation of the sample sections) of the sample leads to increasing displacement values as we move from the base towards the post tip. The sign of the measured displacement is also consistent with our expectations. In fact, the hot air blown by the heat gun produces a non-uniform temperature field where the temperature of the post fibres decreases as we move from the fibres closer to the heat gun (e.g. the fibre including the points M and T, Fig. (3a) towards those more far (e.g. the fibre including the points Q and R, (Fig. 3a). Therefore, the fibres closer to the heat gun will experience a larger elongation compared to those more far and this leads the post to inflect on the side opposite to where the heat gun is located. A displacement with a sign opposite to that found in the experiments would mean, obviously, that the inflection takes place in the side opposite to the one shown in Fig. (3a).

The proposed technique presents some limitations. First of all, the processing of the acquired images is not automatic and the user has to make a number of choices such as the shape and the dimension of the band pass filter to be implemented in the Fourier space. A possible strategy that can be adopted to overcome this limitation consists in performing a large number of experiments on a wide variety of posts (or other dental materials) and finding, for each tested material, the optimal processing parameters; therefore, these parameters can be implemented in ad hoc routine that automatically executes the processing of the acquired images hence limiting the user intervention. Second, the technique requires a thorough and time-expensive calibration process that can take two to five hours. However, once the calibration process was terminated, the set-up can be utilized for measuring the displacement of a large number of samples. For example, to measure the displacements of all the forty samples analyzed in this study, calibration was done once and for all. 

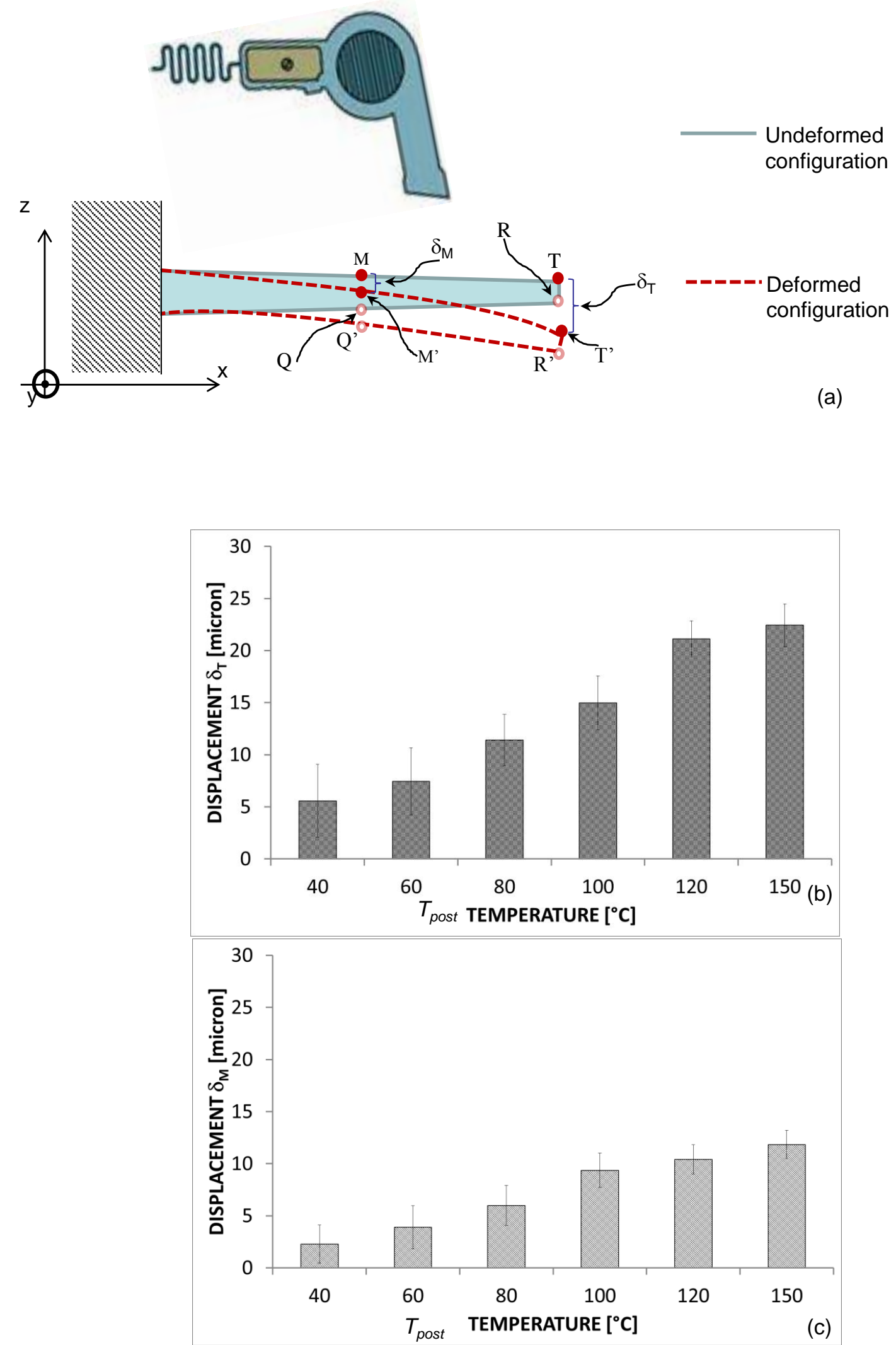

Fig. (3). Due to the thermal loading, the sample experiences an inflexion and the points $\mathrm{T}$ and $\mathrm{M}$ are subjected to displacements $\delta_{\mathrm{T}}$ and $\delta_{\mathrm{M}}$, respectively (a). Average values and standard deviation of the displacements measured at points $\mathrm{T}(\mathbf{b})$ and $\mathrm{M}(\mathbf{c})$ for the different temperatures $T_{\text {post }}$. 
In spite of these limitations, as stated above, the displacement values measured with the proposed system are consistent with the physics of the problem and with our expectations. Furthermore, the values of the standard deviation computed, for each of the tested temperature $T_{\text {post }}$, over the forty tested samples appear reasonably small thus indicating the rather good reliability of the proposed optical technique. These values of standard deviation can certainly be explained with: (i) the differences intrinsically present in the resin matrix or in the glass fiber orientation of the different tested samples; (ii) the positioning errors committed every time a sample was removed and replaced by another one. As demonstrated in a previous study [36] the projection moiré technique has the potentiality of providing results with an accuracy of the order of $1 / 500$ of the sensitivity $\Delta S$ of the system which means, in this case, about half a micron. Furthermore, the technique appears very suited to monitor the displacement field in a wide range of dimensions that goes from some microns $[36,37]$ to meters $[32,38]$.

It is worthy to note that the issue of identifying the possible materials that can be utilized to fabricate interfaces subjected to temperature changes cannot be addressed by simply determining the thermal expansion coefficient [29]. As stated above, the stress state that creates at the interface depends on different thermal properties as well as on the way they interact mutually. A possible application of the proposed optical set-up consists in implementing it on different samples, all shaped with a specific geometry, made from different dental materials and in comparing the resulting displacement fields. Those materials that exhibit comparable displacement values can be put in contact and utilized to fabricate interfaces. Any possible variation of the temperature field, in fact, will produce similar displacement fields in the two materials thus generating negligible thermal stress values.

Another important advantage of the proposed optical system is that the monitoring of the displacement field occurs via a CCD camera which can acquire images with high frequency. This can be properly exploited to describe and evaluate the displacement field and, hence, the stress state, not only in the stationary but also in the transient conditions.

\section{CONCLUSION}

We presented an optical system that has been utilized to determine the displacement field in endocanalar glass-fibre posts subjected to temperature changes. Measurements were performed on forty samples and the average displacement values registered at the apical and middle regions of the post were determined for six different temperature levels. The rather small values of standard deviation that can be justified with arguments independent of the optical system are a proof of the good reliability of the proposed optical technique. The proposed technique can be utilized to identify all the dental materials that can be utilized to fabricate interfaces subjected to thermal loading.

\section{CONFLICT OF INTEREST}

The authors confirm that this article content has no conflict of interest.

\section{ACKNOWLEDGEMENTS}

Declared none.

\section{REFERENCES}

[1] Goracci C, Ferrari M. Current perspectives on post systems: a literature review. Aust Dent J 2011; 56(Suppl. 1): $77-83$. [http://dx.doi.org/10.1111/j.1834-7819.2010.01298.x] [PMID: 21564118]

[2] Dietschi D, Duc O, Krejci I, Sadan A. Biomechanical considerations for the restoration of endodontically treated teeth: a systematic review of the literature, Part II (Evaluation of fatigue behavior, interfaces, and in vivo studies). Quintessence Int 2008; 39(2): 117-29. [PMID: 18560650]

[3] Dikbas I, Tanalp J. An overview of clinical studies on fiber post systems. Sci. World J 2013; p. 171380.

[4] Drummond JL. Degradation, fatigue, and failure of resin dental composite materials. J Dent Res 2008; 87(8): 710-9. [http://dx.doi.org/10.1177/154405910808700802] [PMID: 18650540]

[5] Yang A, Lamichhane A, Xu C. Remaining coronal dentin and risk of fiber-reinforced composite post-core restoration failure: a meta-analysis. Int J Prosthodont 2015; 28(3): 258-64. [http://dx.doi.org/10.11607/ijp.4157] [PMID: 25965640]

[6] Sornkul E, Stannard JG. Strength of roots before and after endodontic treatment and restoration. J Endod 1992; 18(9): 440-3. [http://dx.doi.org/10.1016/S0099-2399(06)80845-9] [PMID: 9796512]

[7] Akkayan B, Gülmez T. Resistance to fracture of endodontically treated teeth restored with different post systems. J Prosthet Dent 2002; 87(4): 431-7. [http://dx.doi.org/10.1067/mpr.2002.123227] [PMID: 12011860] 
[8] Monticelli F, Osorio R, Sadek FT, Radovic I, Toledano M, Ferrari M. Surface treatments for improving bond strength to prefabricated fiber posts: a literature review. Oper Dent 2008; 33(3): 346-55. [http://dx.doi.org/10.2341/07-86] [PMID: 18505227]

[9] Balbosh A, Kern M. Effect of surface treatment on retention of glass-fiber endodontic posts. J Prosthet Dent 2006; 95(3): $218-23$. [http://dx.doi.org/10.1016/j.prosdent.2006.01.006] [PMID: 16543019]

[10] Skupien JA, Sarkis-Onofre R, Cenci MS, Moraes RR, Pereira-Cenci T. A systematic review of factors associated with the retention of glass fiber posts. Braz Oral Res 2015; 29: S1806-83242015000100401. [http://dx.doi.org/10.1590/1807-3107BOR-2015.vol29.0074] [PMID: 26083089]

[11] OKeefe KL, Miller BH, Powers JM. In vitro tensile bond strength of adhesive cements to new post materials. Int J Prosthodont 2000; 13(1): 47-51.

[http://dx.doi.org/10.1111/j.1532-849X.2002.00025.x] [PMID: 11203608]

[12] Gallo JR III, Miller T, Xu X, Burgess JO. In vitro evaluation of the retention of composite fiber and stainless steel posts. J Prosthodont 2002; 11(1): 25-9.

[http://dx.doi.org/10.1111/j.1532-849X.2002.00025.x] [PMID: 11935507]

[13] Al-harbi F, Nathanson D. In vitro assessment of retention of four esthetic dowels to resin core foundation and teeth. J Prosthet Dent 2003; 90(6): 547-55. [http://dx.doi.org/10.1016/j.prosdent.2003.09.014] [PMID: 14668755]

[14] Qualtrough AJ, Chandler NP, Purton DG. A comparison of the retention of tooth-colored posts. Quintessence Int 2003; 34(3): 199-201. [PMID: 12731601]

[15] Mendoza DB, Eakle WS, Kahl EA, Ho R. Root reinforcement with a resin-bonded preformed post. J Prosthet Dent 1997; 78(1): 10-4. [http://dx.doi.org/10.1016/S0022-3913(97)70081-7] [PMID: 9237140]

[16] Corsalini M, Genovese K, Lamberti L, Pappalettere C, Carella M, Carossa S. A laboratory comparison of individual Targis/Vectris posts with standard fiberglass posts. Int J Prosthodont 2007; 20(2): 190-2. [PMID: 17455443]

[17] Grassi FR, Pappalettere C, Di Comite M, et al. Effect of different irrigating solutions and endodontic sealers on bond strength of the dentinpost interface with and without defects. Int J Med Sci 2012; 9(8): 642-54. [http://dx.doi.org/10.7150/ijms.4998] [PMID: 23055816]

[18] Di Comite M, Crincoli V, Fatone L, et al. Quantitative analysis of defects at the dentin-post space in endodontically treated teeth. Materials (Basel) 2015; 8: 3268-83. [http://dx.doi.org/10.3390/ma8063268]

[19] Soares CJ, Castro CG, Santos Filho PC, Soares PV, Magalhaes D, Martins LR. Two-dimensional FEA of dowels of different compositions and external surface configurations. J Prosthodont 2009; 18(1): 36-42. [http://dx.doi.org/10.1111/j.1532-849X.2008.00367.x] [PMID: 18798782]

[20] Mezzomo LA, Corso L, Marczak RJ, Rivaldo EG. Three-dimensional FEA of effects of two dowel-and-core approaches and effects of canal flaring on stress distribution in endodontically treated teeth. J Prosthodont 2011; 20(2): 120-9.

[http://dx.doi.org/10.1111/j.1532-849X.2010.00669.x] [PMID: 21284758]

[21] Lucena-Martín C, González-López S, Navajas-Rodríguez de Mondelo JM. The effect of various surface treatments and bonding agents on the repaired strength of heat-treated composites. J Prosthet Dent 2001; 86(5): 481-8. [http://dx.doi.org/10.1067/mpr.2001.116775] [PMID: 11725276]

[22] Lewis R, Smith BG. A clinical survey of failed post retained crowns. Br Dent J 1988; 165(3): 95-7. [http://dx.doi.org/10.1038/sj.bdj.4806505] [PMID: 3048342]

[23] Mentink AG, Creugers NH, Meeuwissen R, Leempoel PJ, Käyser AF. Clinical performance of different post and core systemsresults of a pilot study. J Oral Rehabil 1993; 20(6): 577-84. [http://dx.doi.org/10.1111/j.1365-2842.1993.tb01645.x] [PMID: 10412480]

[24] Powers J, Wataha J. Dental Materials Properties and manipulation. 10 ${ }^{\text {th }}$ ed. Netherland: Elsevier 2013.

[25] Versluis A, Douglas WH, Sakaguchi RL. Thermal expansion coefficient of dental composites measured with strain gauges. Dent Mater 1996; 12(5): 290-4. [http://dx.doi.org/10.1016/S0109-5641(96)80036-4] [PMID: 9170996]

[26] Tezvergil A, Lassila LV, Vallittu PK. The effect of fiber orientation on the thermal expansion coefficients of fiber-reinforced composites. Dent Mater 2003; 19(6): 471-7. [http://dx.doi.org/10.1016/S0109-5641(02)00092-1] [PMID: 12837394]

[27] Sideridou I, Achilias DS, Kyrikou E. Thermal expansion characteristics of light-cured dental resins and resin composites. Biomaterials 2004; 25(15): 3087-97.

[http://dx.doi.org/10.1016/j.biomaterials.2003.09.078] [PMID: 14967543]

[28] Saitoh M, Masutani S, Kojima T, Saigoh M, Hirose H, Nishiyama M. Thermal properties of dental materialscavity liner and pulp capping agent. Dent Mater J 2004; 23(3): 399-405. [http://dx.doi.org/10.4012/dmj.23.399] [PMID: 15510872] 
[29] Anusavice K, Shen C, Rawls HR. Phillips' Science of Dental Materials. $12^{\text {th }}$ ed. USA: Saunders 2012.

[30] Bodzenta J, Burak B, Nowak M, Pyka M, Szałajko M, Tanasiewicz M. Measurement of the thermal diffusivity of dental filling materials using modified Angströms method. Dent Mater 2006; 22(7): 617-21. [http://dx.doi.org/10.1016/j.dental.2005.05.016] [PMID: 16198406]

[31] Ellakwa AE, Morsy MA, El-Sheikh AM. Effect of aluminum oxide addition on the flexural strength and thermal diffusivity of heatpolymerized acrylic resin. J Prosthodont 2008; 17(6): 439-44. [http://dx.doi.org/10.1111/j.1532-849X.2008.00318.x] [PMID: 18482365]

[32] Sciammarella CA, Lamberti L, Boccaccio A. General model for moiré contouring. Part 1: theory. Opt Eng 2008; 47 : 033605. [http://dx.doi.org/10.1117/1.2899039]

[33] Sciammarella CA, Lamberti L, Boccaccio A, Cosola E, Posa D. General model for moiré contouring. Part 2: applications. Opt Eng 2008; 47: 033606.

[http://dx.doi.org/10.1117/1.2899040]

[34] Boccaccio A, Casavola C, Lamberti L, Pappalettere C. Structural response of polyethylene foam-based sandwich panels subjected to edgewise compression. Materials (Basel) 2013; 6: 4545-64. [http://dx.doi.org/10.3390/ma6104545]

[35] Boccaccio A, Martino F, Pappalettere C. A novel moiré-based optical scanning head for high-precision contouring. Int J Adv Manuf Technol 2015; 80: 47-63.

[http://dx.doi.org/10.1007/s00170-015-7002-9]

[36] Sciammarella CA, Lamberti L, Boccaccio A, Sciammarella FM. High precision contouring with the projection moiré and related methods, a review. Strain 2011; 47(s2): 43-64. [http://dx.doi.org/10.1111/j.1475-1305.2010.00733.x]

[37] Sciammarella CA, Boccaccio A, Lamberti L, et al. Measurements of deflection and residual stress in thin films utilizing coherent light projection/reflection moiré interferometry. Exp Mech 2013; 53: 977-87. [http://dx.doi.org/10.1007/s11340-012-9699-9]

[38] Sciammarella CA, Lamberti L, Boccaccio A. High precision contouring utilizing the moiré method. Proceedings of the $11^{\text {th }}$ International Congress and Exhibition on Experimental and Applied Mechanics. Orlando, Florida USA. 2008; pp. 1495-510.

(C) Corsalini et al.; Licensee Bentham Open

This is an open access article licensed under the terms of the Creative Commons Attribution-Non-Commercial 4.0 International Public License (CC BY-NC 4.0) (https://creativecommons.org/licenses/by-nc/4.0/legalcode), which permits unrestricted, non-commercial use, distribution and reproduction in any medium, provided the work is properly cited. 